EXTENDED REPORT

\title{
Development of the PsAQoL: a quality of life instrument specific to psoriatic arthritis
}

\author{
S P McKenna, L C Doward, D Whalley, A Tennant, P Emery, D J Veale
}

Ann Rheum Dis 2004;63:162-169. doi: 10.1136/ard.2003.006296

See end of article for authors' affiliations

.....................

Correspondence to:

Dr S P McKenna, Galen

Research, Enterprise

House, Manchester

Science Park, Lloyd Street

North, Manchester M15

6SE, UK; smckenna@

galen-research.com

Accepted 27 March 2003
Background: Patient reported outcome measures used in studies of psoriatic arthritis (PsA) have been found to be inadequate for determining the impact of the disease from the patient's perspective.

Objective: To produce the PsAQoL, a PsA-specific quality of life (QoL) instrument, employing the needs based model of QoL that would be relevant and acceptable to respondents, valid, and reliable.

Methods: Content was derived from qualitative interviews conducted with patients with PsA. Face and content validity were assessed by field test interviews with a new sample of patients with PsA. A postal survey was conducted to improve the scaling properties of the new measure. Finally, a test-retest postal survey was used to identify the final measure and to test its scaling properties, reliability, internal consistency, and validity.

Results: Analysis of the qualitative interview transcripts identified a 51 item questionnaire. Field test interviews confirmed the acceptability and relevance of the measure. Analysis of data from the first postal survey $(n=94)$ reduced the questionnaire to 35 items. Rasch analysis of data from the test-retest survey $(n=286)$ identified a 20 item version of the PsAQoL with good item fit. This version had excellent internal consistency $(\alpha=0.91)$, test-retest reliability $(0.89)$, and validity.

Conclusions: The PsAQoL is a valuable tool for assessing the impact of interventions for PsA in clinical studies and trials. It is well accepted by patients, taking about three minutes to complete, is easy to administer, and has excellent scaling and psychometric properties.
$\mathrm{P}$ soriatic arthritis (PsA) is an inflammatory form of arthritis that occurs in association with psoriasis and is seronegative for rheumatoid factor. Gladman and Espinoza suggest that PsA may occur in almost $1 \%$ of the population. ${ }^{1}$ PsA can present as asymmetrical oligoarthritis (in which few joints are affected); symmetrical polyarthritis (indistinguishable from rheumatoid arthritis); and predominant spondylitis (with spinal involvement) which can be indistinguishable from ankylosing spondylitis. ${ }^{2}$ The multifaceted nature of the presentation of the disease is subsequently mirrored in the complex manifestations of impairment and limitation of activity experienced by patients. $^{34}$

The choice of outcome measure(s) for such complex diseases presents a dilemma, often resulting in the need for numerous instruments in an attempt to assess the different impairments, activity limitations, and resulting participation restriction experienced. Over the past decade several researchers have attempted to employ existing patient completed instruments to determine the impact of PsA. For example, a number of authors have found that the Health Assessment Questionnaire (HAQ) is not a useful measure for assessing the impact of the disease. Blackmore and colleagues found that scores on the HAQ and the HAQ modified for spondyloarthropathy were unrelated to PsA disease severity. ${ }^{5}$ An adapted version of the HAQ, specifically designed for use in PsA was found not to be suitable for determining disability associated with the condition. ${ }^{6}$

Duffy and colleagues attempted to validate the Arthritis Impact Measurement Scale (AIMS) for patients with PsA. ${ }^{7}$ Unfortunately, they did not report on the reliability of the scale-concentrating only on construct validity. The AIMS sections were found to have low to moderate correlations with clinical measures of function, disease activity, and disease severity. Consequently, few conclusions could be drawn from the study. Husted and associates conducted a similar study with the adapted AIMS-AIMS2. ${ }^{8}$ Again, no attempt was made to assess reliability, and low to moderate correlations were found with measures of function and disease activity. Correlations between AIMS2 scores and disease severity were uniformly low $(-0.06$ to 0.27$)$. The authors concluded that AIMS2 is less suitable for use with patients with PsA than the original AIMS instrument.

The same authors explored the responsiveness of AIMS to changes in traditional clinical indicators of health status. ${ }^{9}$ Unfortunately, they used AIMS at the first administration and AIMS2 four years later. Only the pain component score was significantly related to change in the number of active joints, suggesting that the measure is unresponsive to clinical changes in health status. In a later study, ${ }^{10}$ scores on the HAQ, AIMS2 and SF-36 were unable to show differences in health status between patients who had and had not received surgery for their PsA. However, the groups were not matched for disease severity.

Taccari and colleagues found predominantly low associations between indicators of disease activity and scores on both the HAQ and AIMS in patients with PsA. ${ }^{11}$ Unsurprisingly, given its emphasis on physical disability, the HAQ was unable to inform on the effect of the psoriatic lesions experienced by patients.

Attempts have also been made to validate the Short Form36 (SF-36) for use in PsA. ${ }^{12}$ Again, unfortunately, no attempt was made to measure the instrument's reliability with this patient group. Scores on the SF-36 were found to correlate moderately with clinical indicators of function, pain, and

Abbreviations: AIMS, Arthritis Impact Measurement Scales; DIF, differential item functioning; $H A Q$, Health Assessment Questionnaire; NHP, Nottingham Health Profile; PsA, psoriatic arthritis; QoL, quality of life; SF-36, Short Form-36; VAS, visual analogue scale 
arthritis activity. However, SF-36 scores were unrelated to disease severity (particularly, psoriasis severity)-again reflecting the bias of the instrument towards impairment and physical disability.

The responsiveness to change of the HAQ, AIMS2, and SF36 in patients with PsA has also been investigated. ${ }^{4}$ All three instruments performed poorly, although it appears that the SF-36 was marginally more responsive. The lack of responsiveness of these instruments to articular changes suggests that all three would be of limited value in a clinical trial.

To overcome these problems it was decided to develop a PsA-specific outcome measure. The growing interest in the assessment of quality of life (QoL), particularly in chronic disabling conditions, argued in favour of focusing on this outcome construct. The model adopted was the needs based model of QoL ${ }^{15-19}$ which has been successfully applied in the development of disease-specific QoL measures for rheumatoid arthritis,,$^{20}$ ankylosing spondylitis, ${ }^{21}$ and systemic lupus erythematosus. ${ }^{22}$ The measurement model argues that disease related impairment and disability influence a person's ability to meet his or her needs. QoL is defined as the extent to which needs are fulfilled. This model is particularly useful in a condition such as PsA, as the reason for needs being frustrated is irrelevant, allowing arthritic and dermatological impacts to be summarised in a single outcome measure. QoL assessment is intended to provide an accurate summary of the impact of a disease from the perspective of the patient. It is important to note that it is not intended to determine disease severity or to aid in deciding on the most appropriate intervention for individual patients.

This paper describes the development and validation of the PsAQoL, a PsA-specific QoL instrument designed for use in clinical trials and for assessing patient reported outcome in routine clinical practice.

\section{METHODS}

\section{Stages in instrument development}

Table 1 lists the stages in the PsAQoL development programme.

\section{Patients}

Different patient samples were employed at each stage of instrument development and testing. Stages 1, 3, and 4 employed patients diagnosed with PsA currently attending hospital outpatient clinics in Leeds. As a larger sample was required for the second postal survey (stage 5), patients were recruited with the help of the Psoriatic Arthropathy Alliance. The questionnaire was included in a routine mailing to its 450 members. Participants in this survey were required to provide information on the history of the PsA, aspects of its current status, and current use of drugs.

\section{Item generation}

The content of the PsAQoL was derived from unstructured, qualitative interviews conducted with patients with PsA in their own homes. This method of item generation fulfils a

Table 1 Stages in PsAQoL development

\begin{tabular}{ll}
\hline Stage & Activity \\
\hline 1 & Qualitative patient interviews \\
2 & $\begin{array}{l}\text { Content analysis of interview transcripts and } \\
\text { identification of potential items for PsAQoL }\end{array}$ \\
3 & Field test patient interviews \\
4 & Postal survey for item reduction \\
5 & Test-retest postal survey to establish \\
& reliability and construct validity \\
\hline
\end{tabular}

basic requirement of QoL instruments-namely, that their content should be generated from relevant patients. ${ }^{23}$ This is because it ensures that the content of the final instrument is relevant to the target population and that issues considered important by patients are not omitted.

The interviews, which were audio recorded, were informal, focused conversations and were designed to explore how PsA affects the lives of patients. For example, interviewees were encouraged to consider how functional limitations that they experienced influenced their ability to meet their needs.

Transcripts were produced from the interview tapes, which were then wiped clean to maintain confidentiality. Information that would allow the identification of the interviewee was also omitted from the typed transcripts.

\section{Selection of items for the draft questionnaire}

The interview transcripts were subjected to content analysis to identify potential items for the questionnaire. Items were selected for inclusion where they were relevant to the needs model, were applicable to all potential respondents, reflected a single idea, were unambiguous, and were short and simple. Duplicated, idiosyncratic, and badly phrased items were rejected and a draft questionnaire constructed from the remaining items.

\section{Field test methodology}

Field test interviews were used to check on the relevance and comprehensiveness of the draft PsAQoL and to see whether patients could understand the questionnaire and complete it without problems. This was the final stage at which the wording of items could be changed to improve comprehension. It was also possible for interviewees to suggest additional items. Interviews were conducted at rheumatology outpatient clinics. Potential participants were approached in the waiting room at the clinic and had the nature of the project explained to them. If willing to take part, they were interviewed one at a time in a quiet private office.

The questionnaire was completed in the presence of an interviewer who noted whether the participants read the instructions, had any obvious difficulties, or hesitated over particular items. On completing the questionnaire, participants were invited to comment on the suitability of questionnaire items, instructions, and response categories. They were also asked specific questions about four of the items to see how they were interpreted or to check on the most appropriate wording. After this a second draft questionnaire was produced.

\section{Postal survey 1}

This survey was conducted primarily to reduce further the number of items included in the draft PsAQoL. Patients with PsA were sent a questionnaire booklet to complete consisting of demographic questions and the PsAQoL. Rasch analysis was conducted on the resulting data to identify items that failed to fit the underlying measurement construct (QoL) and/or that worked differentially by age or disease duration (above or below the median). At this stage, only the most grossly misfitting items or those with large differential item functioning (DIF) were removed.

\section{Postal survey 2}

The purpose of the second postal survey was to identify the final set of items to be included in the PsAQoL and to determine the scaling properties, internal consistency, reliability (reproducibility), and construct validity of the revised measure.

As a larger sample was required for this survey, patients were recruited with the help of the Psoriatic Arthropathy 
Alliance. The questionnaire was included in a routine mailing to its 450 members.

Members of the Psoriatic Arthropathy Alliance who volunteered to participate in the survey were sent a revised questionnaire booklet consisting of the demographic questionnaire (including questions about patient perceived disease activity and severity of illness), the current version of the PsAQoL, the Nottingham Health Profile (NHP), and a reply paid envelope. The NHP is a measure of perceived distress that consists of six sections: energy level, pain, physical mobility, sleep, social interactions, and emotional reactions. ${ }^{24}$ This measure was selected as the comparator measure as it is generally well accepted by patients and has better psychometric properties than the other generic health status measures. ${ }^{24-26}$ Patients who completed and returned this pack and gave permission to be approached again, were sent a similar package timed to arrive two weeks later. It was not possible to send follow up questionnaires as a condition of the access to the society's database was that its membership should remain anonymous unless they responded to the first mailing and specifically gave permission to be approached for the test-retest mailing.

Data from the PsAQoL were again fitted to the Rasch model to confirm that the items formed a unidimensional scale, that they each represented a different amount of QoL (hierarchical ordering), and that there was an absence of DIF. The analyses also determined whether the scale operated at the ordinal or interval level. Internal consistency, test-retest reliability, and construct validity were then determined based on the final PsAQoL item set.

\section{Statistics}

\section{Rasch model}

The application of the Rasch model ensures that the fundamental scaling properties of an instrument (for example, unidimensionality and level of measurement) are assessed in addition to the traditional psychometric assessments of reliability and external construct validity. ${ }^{27}$ In the present context, the Rasch model adopts the premise that the likelihood of a person affirming a particular item depends on both the level of QoL of the person and on the level of QoL represented by the item.

One way in which unidimensionality may be compromised is through DIF. ${ }^{28}$ The basis of the DIF approach lies in the item response function, the S-shaped trace of the proportion of people at the same level of QoL who affirm an item. Under the requirement that the ability under consideration is unidimensional, if the item measures the same QoL across groups then, except for random variations, the same curve is found irrespective of the nature of the group for which a function is plotted. ${ }^{28}$ Thus data from the draft PsAQoL measures were fitted to the Rasch model and all items tested for DIF by age and sex. Items that did not fit the model and those displaying significant DIF were removed from the scale. Fit to the model was assessed with a significance level of 0.01 to account for multiple testing.

Internal consistency (the degree of item interrelatedness) was assessed by Cronbach's alpha coefficients. A value of 0.70 or above was taken to be indicative of adequate internal consistency. ${ }^{29}$ The reliability of the PsAQoL (an estimate of the instrument's reproducibility over time, assuming that no change in condition has taken place) was assessed using the test-retest method. Scores on the instrument at each administration were correlated, with a Spearman rank correlation coefficient of at least 0.85 considered necessary to indicate that the PsAQoL would be suitable for use in a clinical trial or for monitoring individual patients. ${ }^{30}$

Construct validity was assessed by relating scores on the PsAQoL to those on the NHP and to perceived general health, reported severity of illness, and patient perceived disease activity. It was predicted that there would be moderate associations between the PsAQoL and the NHP sections, indicating that they assess related but different outcome constructs. It was also suggested that QoL would be worse for respondents reporting poorer general health or those considering their PsA to be severe.

\section{Ethics}

Ethical approval was given by the United Leeds Hospital Trust ethics committee.

\section{RESULTS}

\section{Findings from qualitative interviews (stage 1)}

Interviews were conducted with 48 ( 32 male, 16 female) patients with a mean (SD) age of 46.9 (13.4) years. Thirty eight $(79 \%)$ were married or cohabiting and $22(46 \%)$ were full time employed. Time since diagnosis ranged from 1 to 40 (mean 12.1) years, and $36(75 \%)$ of the sample were currently experiencing both psoriatic and arthritic symptoms. Twenty nine $(60 \%)$ interviewees were currently experiencing a flare up of their condition.

The interviews lasted between 0.5 and 2.0 hours. PsA was reported to have a major impact on many aspects of the interviewees' lives. The main issues raised could be categorised into four main experiences or events:

- Reaction to diagnosis: preoccupation with the illness and grieving over loss of previous lifestyle.

- Life changes: reduced ability to fulfil personal roles, social life, and work. Loss of motivation to take part in, and reduced pleasure gained from, activities.

- Adaptation and acceptance: the need to adapt day to day routines and to acknowledge that such changes are necessary.

- Concerns for the future: uncertainty over future capabilities, fear of potential worsening of the condition, and the adverse effects of treatments and loss of independence.

It was clear from the interviews that as a result of PsA several needs could not be fulfilled. These included needs for control over the illness, stimulation, independence, spontaneity, companionship, communication, to feel valued, and to have a purpose in life.

Selection of items for the draft questionnaire (stage 2) As far as possible, items for the questionnaire consisted of wording taken from the transcripts. In some cases it was necessary to shorten the quotation, change the word order, or express them as first person statements or in the present tense. The item selection process yielded 169 potential questionnaire items. Removal of duplicate, idiosyncratic, and poorly phrased items resulted in a pool of 51 items for the first version of the questionnaire. A dichotomous ("true/ not true") response format was selected, as previous studies had indicated that this was the most appropriate for such questionnaires. $^{31}$

\section{Field testing for face and content validity (stage 3)}

Fifteen patients (nine male, six female) were interviewed. The sample had a mean (SD) age of 48.1 (10.8) years. All interviewees were married or cohabiting and eight (53\%) were working full time. There was a mean (SD) period of 14.0 (10.1) years since diagnosis of PsA and 13 (87\%) of the sample were experiencing both psoriatic and arthritic symptoms. Four $(27 \%)$ of the sample were not currently experiencing a flare up of their condition.

The interviewees took a median of five (range 310) minutes to complete the 51 item questionnaire. The 
PsAQoL was considered to be well presented and acceptable to patients. There did not appear to be any problems during the completion of the questionnaire and no items were determined to be inappropriate. During the interview, patients were asked if there were any issues that had been omitted from the questionnaire. Some issues were raised but these tended to be idiosyncratic, such as difficulties experienced with local public transport.

Although interviewees commented that the questionnaire was relevant and covered pertinent issues they had experienced because of their illness, problems were encountered with eight of the items and some duplication of ideas was found. Problems included some interviewee's inability to understand the word spontaneity used in one item, vaguely expressed items, and others where there was a perceived lack of specificity to PsA. Five items were removed from the questionnaire and the wording of three more was changed as a result of the interviews, resulting in a 46 item scale which was taken forward for further testing.

\section{Exploratory analysis - first postal survey (stage 4)}

Demographic details of participants who took part in both postal surveys are shown in table 2 . The table also includes patient reported information about health status.

Questionnaire packs were distributed to 120 patients and returned by 94 , a response rate of $78 \%$. Rasch analyses were performed on the data to identify items for which misfit or DIF were most problematic. While some items were found to misfit, DIF was minimal. As a result of these analyses, 11 items were removed from the PsAQoL, producing a 35 item version that was taken forward to stage 5 .

\section{Internal and external construct validity and reliability-second postal survey (stage 5)}

Completed booklets were returned by 286 members of the Psoriatic Arthropathy Alliance. Of those who responded, 237 $(83 \%)$ also returned a completed questionnaire at time 2 . As this was a validation study, measures with one or more missing responses were excluded from the analyses. Table 3 shows descriptive scores on the main outcome measures (including the final 20 item PsAQoL-see below).

Fitting data to the Rasch model again identified misfit in this larger sample. Fifteen additional items were removed owing to misfit or DIF. The 20 item solution resulted in a good overall item fit mean (SD) of 0.183 (1.115) and person fit mean (SD) of $-0.232(0.807)$; and item trait interaction $\chi^{2}$ of $96.1(\mathrm{df}=80 ; \mathrm{p}=0.106)$. Individual item difficulty level (QoL impact) ranged from -2.02 logits to +2.8 logits, and individual item fit statistics ranged from $\mathrm{p}$ values of 0.954 to 0.017. A person separation index of 0.922 indicated that the scale could differentiate four or more groups of patients along the continuum. Table 4 gives the best and worst fitting items of this solution.

The 20 item solution was tested again in the retest sample. Once again this resulted in a good overall item fit mean (SD) of 0.047 (1.508) and person fit mean (SD) of -0.205 (0.704); and item trait interaction $\chi^{2}$ of $79.9(\mathrm{df}=60 ; \mathrm{p}=0.043)$. Individual item difficulty level (QoL impact) ranged from -2.18 logits to +2.86 logits and individual item fit statistics ranged from $\mathrm{p}$ values of 0.976 to 0.010 . A person separation index of 0.930 indicated that once again the scale could differentiate four or more groups of patients along the continuum. This second analysis confirmed the robustness of the internal construct validity of the scale.

\section{Reliability and internal consistency of the PsAQoL}

The test-retest Spearman rank correlation coefficient was 0.89 , indicating that the measure has excellent reliability, producing low levels of random measurement error
Table 2 Characteristics and health status of respondents participating in postal surveys

\begin{tabular}{|c|c|c|c|c|}
\hline & \multicolumn{2}{|c|}{$\begin{array}{l}\text { Postal survey } 1 \\
\text { ( } \mathrm{n}=94)\end{array}$} & \multicolumn{2}{|c|}{$\begin{array}{l}\text { Postal survey } 2 \\
(\mathrm{n}=286)\end{array}$} \\
\hline & No & $\%$ & No & $\%$ \\
\hline \multicolumn{5}{|l|}{ Sex } \\
\hline Male & 31 & 33 & 93 & 32.5 \\
\hline Female & 62 & 67 & 193 & 67.5 \\
\hline \multicolumn{5}{|l|}{ Age (years) } \\
\hline Mean (SD) & \multirow{2}{*}{\multicolumn{2}{|c|}{$\begin{array}{l}48.0(12.7) \\
24-89\end{array}$}} & \multicolumn{2}{|c|}{$50.6(12.6)$} \\
\hline Range & & & & \\
\hline \multicolumn{5}{|l|}{ Marital status } \\
\hline Married/living as & 59 & 63.4 & 213 & 74.7 \\
\hline Other & 34 & 36.6 & 72 & 25.3 \\
\hline \multicolumn{5}{|l|}{ Employment status } \\
\hline Working full time & 25 & 27.2 & 71 & 25.1 \\
\hline Working part time & 12 & 13.0 & 36 & 12.7 \\
\hline Home maker & 6 & 6.5 & 30 & 10.6 \\
\hline Other & 49 & 53.3 & 146 & 51.6 \\
\hline \multicolumn{5}{|c|}{ Time since diagnosis (years) } \\
\hline Mean (SD) & \multirow{2}{*}{\multicolumn{2}{|c|}{$\begin{array}{l}13.8(11.3) \\
1-62\end{array}$}} & \multicolumn{2}{|c|}{$12.5(10.2)$} \\
\hline Range & & & & ( \\
\hline \multicolumn{5}{|c|}{ Perceived current health status } \\
\hline Very good & 7 & 7.5 & 12 & 4.2 \\
\hline Good & 22 & 23.7 & 99 & 34.9 \\
\hline Fair & 43 & 46.2 & 129 & 45.4 \\
\hline Poor & 21 & 22.6 & 44 & 15.4 \\
\hline \multicolumn{5}{|c|}{ Perceived current severity of psoriasis } \\
\hline Mild & 40 & 43.5 & 125 & 45.6 \\
\hline Moderate & 33 & 35.9 & 96 & 35.0 \\
\hline Quite severe & 16 & 17.4 & 44 & 16.1 \\
\hline Severe & 3 & 3.3 & 9 & 3.3 \\
\hline \multicolumn{5}{|c|}{ Perceived current severity of arthritis } \\
\hline Mild & 19 & 20.4 & 55 & 19.9 \\
\hline Moderate & 38 & 40.9 & 119 & 43.0 \\
\hline Quite severe & 30 & 32.3 & 83 & 30.0 \\
\hline Severe & 6 & 6.5 & 20 & 7.2 \\
\hline \multicolumn{5}{|c|}{ Current flare up of psoriasis? } \\
\hline Yes & 41 & 48.2 & 111 & 41.0 \\
\hline No & 44 & 51.8 & 160 & 59.0 \\
\hline \multicolumn{5}{|c|}{ Current flare up of arthritis? } \\
\hline Yes & 57 & 62.0 & 149 & 53.6 \\
\hline No & 35 & 38.0 & 129 & 46.4 \\
\hline \multicolumn{5}{|c|}{ Using treatment for psoriasis? } \\
\hline Yes & 63 & 67.7 & 176 & 62.9 \\
\hline No & 30 & 32.3 & 104 & 37.1 \\
\hline \multicolumn{5}{|c|}{ Using drugs for arthritis? } \\
\hline Yes & 73 & 77.7 & 222 & 78.4 \\
\hline No & 21 & 22.3 & 61 & 21.6 \\
\hline
\end{tabular}

(table 5). In contrast, the reliability of the Health visual analogue scale (VAS; 0.72), the QoL VAS (0.78), and that of three of the NHP sections failed to meet the standard required of instruments used in clinical trials. Internal consistency of the PsAQoL was 0.91 at both administrations, demonstrating an adequate degree of interconnectedness of items.

\section{External construct validity}

Moderately high correlations were seen between the PsAQoL and NHP section scores (table 6). The highest correlation was with the energy level section (0.75) - a predictable result reflecting the importance of fatigue on QoL in PsA. Similar levels of correlations were also found between PsAQoL scores and those on the Health and QoL VASs, suggesting that these items were measuring related but different constructs than the PsAQoL.

Scores on the PsAQoL were unrelated to sex, age, or marital status or time since diagnosis. However, as expected, employed respondents had better QoL $(\mathrm{p}<0.001)$. Predictably, PsAQoL scores were also significantly related to perceived current health $(\mathrm{p}<0.001)$ and to scores on the QoL VAS $(p<0.001)$ and those on the Health VAS $(p<0.001)$. 
Table 3 Descriptive scores on the main outcome measures in postal survey 2

\begin{tabular}{llccl}
\hline Measure & No & Median & IQR & Range \\
\hline PsAQoL & 263 & 9.0 & $5-13$ & $0-20$ \\
Health VAS & 273 & 49.0 & $32-69$ & $0-99$ \\
QoL VAS & 274 & 60.0 & $37-75$ & $2-99$ \\
NHP & & & & \\
$\quad$ Energy level & 278 & 66.7 & $33-100$ & $0-100$ \\
Pain & 273 & 50.0 & $25-89$ & $0-100$ \\
Emotional reactions & 276 & 11.1 & $0-33$ & $0-100$ \\
Sleep & 277 & 40.0 & $0-80$ & $0-100$ \\
Social isolation & 279 & 0.0 & $0-20$ & $0-100$ \\
$\quad$ Physical mobility & 274 & 37.5 & $13-50$ & $0-100$ \\
NHPD & 265 & 7.0 & $3-12$ & $0-24$ \\
\hline
\end{tabular}

PsAQoL scores were unrelated to whether or not facial skin was affected, respondents were having a psoriasis flare up, or they were currently being treated for their psoriasis. In contrast, scores on the measure were worse when the hands were affected by psoriasis $(\mathrm{p}<0.001)$ and were significantly related to perceived severity of psoriasis $(p<0.02)$. PsAQoL scores were also significantly related to whether respondents were having a flare up of arthritis $(\mathrm{p}<0.001)$, whether the arthritis was being treated $(p<0.01)$, and the perceived severity of arthritis $(\mathrm{p}<0.001)$.

Figures 1 and 2 illustrate the associations between PsAQoL scores and demographic and health status variables.

\section{DISCUSSION}

Perhaps one reason for the lack of success of patient reported instruments used in studies of PsA is that the condition has both rheumatic and dermatological impacts on patients. No measure is available that is specific to PsA. The HAQ and AIMS are measures developed for use with rheumatic illnesses, and the SF-36 has been found to provide contradictory scores for patients with psoriasis, suggesting either that their health status is better than that of an average population $^{13}$ or that the impact of the illness on patients is greater than that of arthritis, cancer, and myocardial infarction. ${ }^{14}$ The SF-36 is a generic measure of health status and the HAQ and AIMS are intended for use with all rheumatic conditions, implying that their content may not be particularly well focused on the issues of importance in PsA. Furthermore, these measures focus primarily on impairments and activity limitation (disability), adding relatively little information to routine clinical indicators of outcome. Consequently, they do not inform on the overall impact of the condition and its treatment on the patient's QoL. The patients' perspective is crucial when determining the acceptability of an intervention and associated compliance.
The PsAQoL is based on a clear, conceptual model of QoL that has been successfully used in the development of several disease-specific QoL instruments, including measures for rheumatoid arthritis, ankylosing spondylitis, and systemic lupus erythematosus. The items in the measure largely represent the words of individual patients with PsA and were derived directly from qualitative, unstructured interviews. This method fulfils the basic requirement that QoL instruments should be based on information derived directly from patients and ensures that future respondents find the instrument acceptable, comprehensive, and relevant to their condition. The PsAQoL is quick and easy to complete-taking less than five minutes, making it suitable for use in clinical settings.

In rheumatology, Rasch analysis is increasingly seen as the standard approach ensuring quality measurement. ${ }^{32}$ Fitting data from the PsAQoL to the Rasch model confirmed a unidimensional scale with good item stability over time, and minimal DIF. Scales that fit the Rasch model have the added advantage that scores can be transformed to the interval level. This allows valid arithmetic operations such as the calculation of change scores or effect sizes to be applied, an important requirement for all outcome measures in musculoskeletal disorders. ${ }^{33}$

The test-retest reliability and internal consistency of the PsAQoL are excellent, indicating that the instrument is suitable for use in individual patients. For an instrument to have construct validity it must be based on a model of the construct assessed and be shown to have good reliability. ${ }^{34}$ As these requirements are met for the PsAQoL it can be concluded that the measure provides a valid assessment of the construct defined in the model. Additional indications of the validity of the PsAQoL were provided by the moderately high correlations between PsAQoL scores and those on the NHP (perceived distress), the Health VAS and the QoL VAS. Scores on the PsAQoL were also related, as expected, to a

Table 4 Fit of the 20 item PsAQoL to the Rasch Model: Best and worst fitting items

\begin{tabular}{lrrrr}
\hline Item & Location & Residual & \multicolumn{1}{c}{$\chi^{2}$} & p Value \\
\hline Best & & & & \\
I can't do the things I want to do & -1.883 & -0.581 & 0.680 & 0.954 \\
It's too much effort to go out and see people & 0.751 & 0.120 & 2.328 & 0.677 \\
I take it out on people close to me & 0.528 & 0.615 & 2.346 & 0.673 \\
I feel like a prisoner in my own home & 2.442 & 2.000 & 2.784 & 0.595 \\
I'm unable to join in activities with friends or family & 0.609 & 0.315 & 2.806 & 0.591 \\
Worst & & & & \\
It takes me a long time to get going in the morning & -1.626 & -0.482 & 6.205 & 0.184 \\
I am easily irritated by other people & 0.912 & 1.418 & 6.333 & 0.176 \\
I have to keep stopping what I am doing to rest & -1.256 & -0.141 & 7.968 & 0.093 \\
I have to limit what I do each day & -1.960 & 0.561 & 8.240 & 0.083 \\
I often get angry with myself & -0.393 & 2.206 & 12.041 & 0.018 \\
\hline
\end{tabular}




\begin{tabular}{|lll|}
\hline $\begin{array}{l}\text { Table } 5 \text { Test-retest reliability for the main outcome } \\
\text { measures }\end{array}$ & \\
\hline Measure & No & $\begin{array}{l}\text { Test-retest } \\
\text { reliability }\end{array}$ \\
\hline PsAQoL & 211 & 0.89 \\
Health VAS & 232 & 0.72 \\
QoL VAS & 233 & 0.78 \\
NHP & & \\
Energy level & 229 & 0.76 \\
Pain & 225 & 0.87 \\
Emotional reactions & 223 & 0.79 \\
Sleep & 228 & 0.85 \\
Social isolation & 226 & 0.82 \\
Physical mobility & 221 & 0.88 \\
NHPD & 215 & 0.85 \\
\hline & & \\
\hline
\end{tabular}

number of variables, including perceived current health, whether the hands were affected by psoriasis, perceived severity of both psoriasis and arthritis, and whether respondents were having a flare up of their arthritis. It was important to establish that the measure was related to both the dermatological and rheumatological aspects of PsA.

It is acknowledged that the sample used in the second postal survey was self selected and might have included some subjects who did not have PsA. However, the psychometric analyses did not suggest that there were problems with the sample employed.

It also remains to be shown that the PsAQoL is responsive to changes in QoL associated with effective interventions for PsA. Such a property requires that a measure has good reliability and validity, as has been demonstrated in the case of the PSAQoL.

A criticism of disease-specific measures is that they do not allow comparisons to be made across diseases and, consequently, that they cannot form the basis of economic analyses
Table 6 Correlation between PsAQoL and comparator measures

\begin{tabular}{lll}
\hline Comparator measure & No & $\begin{array}{l}\text { Correlation with } \\
\text { PsAQoL }\end{array}$ \\
\hline Health VAS & 253 & -0.64 \\
QoL VAS & 254 & -0.65 \\
NHP & & \\
$\quad$ Energy level & 257 & 0.75 \\
Pain & 252 & 0.68 \\
Emotional reactions & 255 & 0.69 \\
Sleep & 255 & 0.52 \\
Social isolation & 257 & 0.63 \\
$\quad$ Physical mobility & 255 & 0.72 \\
NHPD & 246 & 0.81 \\
\hline
\end{tabular}

comparing the benefits of interventions for different diseases. Modern psychometric techniques overcome this problem through item banking. ${ }^{35}$ Where instruments are designed to measure the same construct it is possible to "co-calibrate" them onto the same underlying metric (logit) scale. The PsAQoL has been explicitly designed to be added to such an item bank by an item selection process that, other things being equal, selects items that are common with other disease-specific scales. This then permits common item equating of different scales and incorporation into a QoL item bank.

It is concluded that the scaling and psychometric properties of the PsAQoL indicate that the instrument can be used with confidence by researchers and clinicians. The instrument represents the first patient based outcome measure specific to PsA and (assuming that it proves to be responsive to change in QoL, as suggested by its psychometric properties) it will be a valuable tool for assessing the impact of PsA and its treatment in clinical settings, trials, and research studies. Such an instrument will allow assessment of the
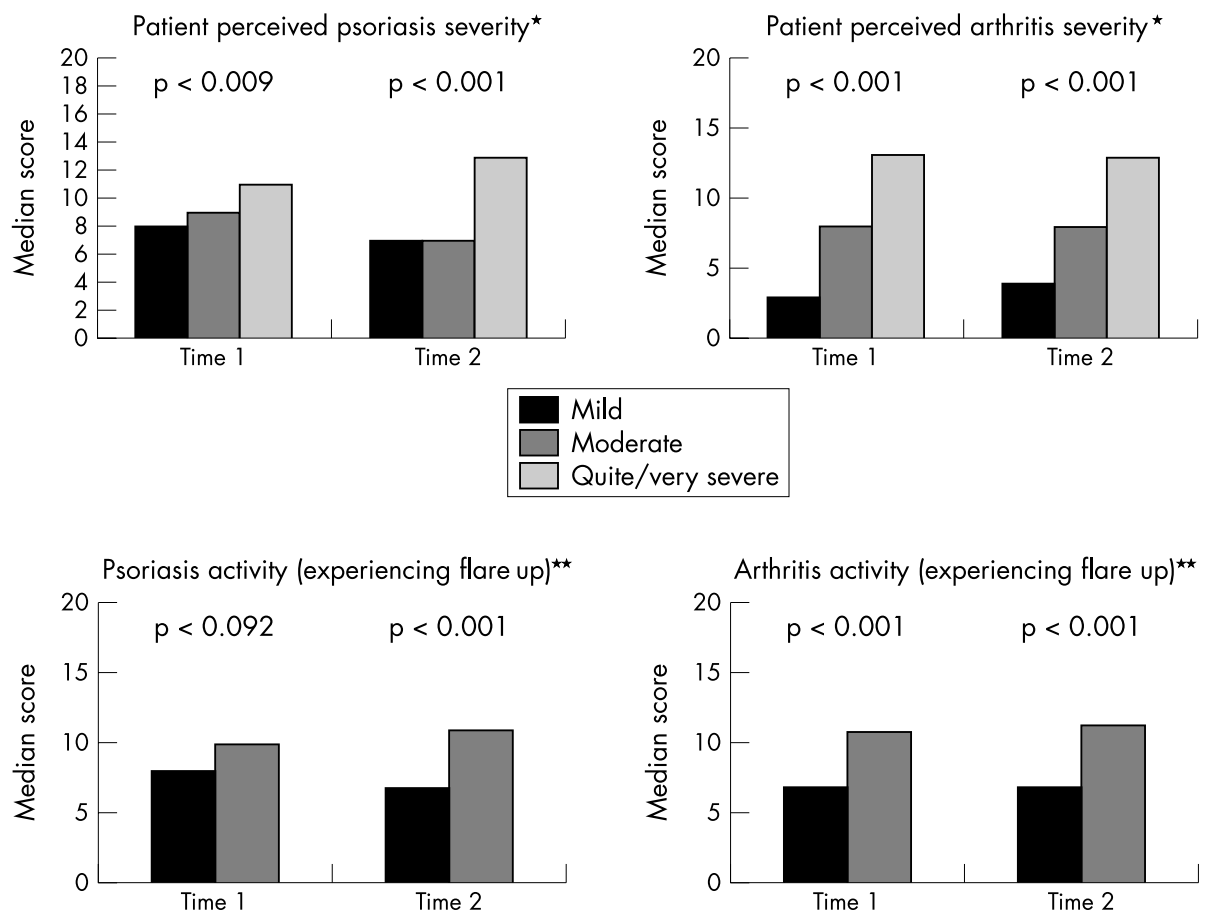

No

Yes

Figure 1 Associations between PsAQoL scores and disease severity and activity. 

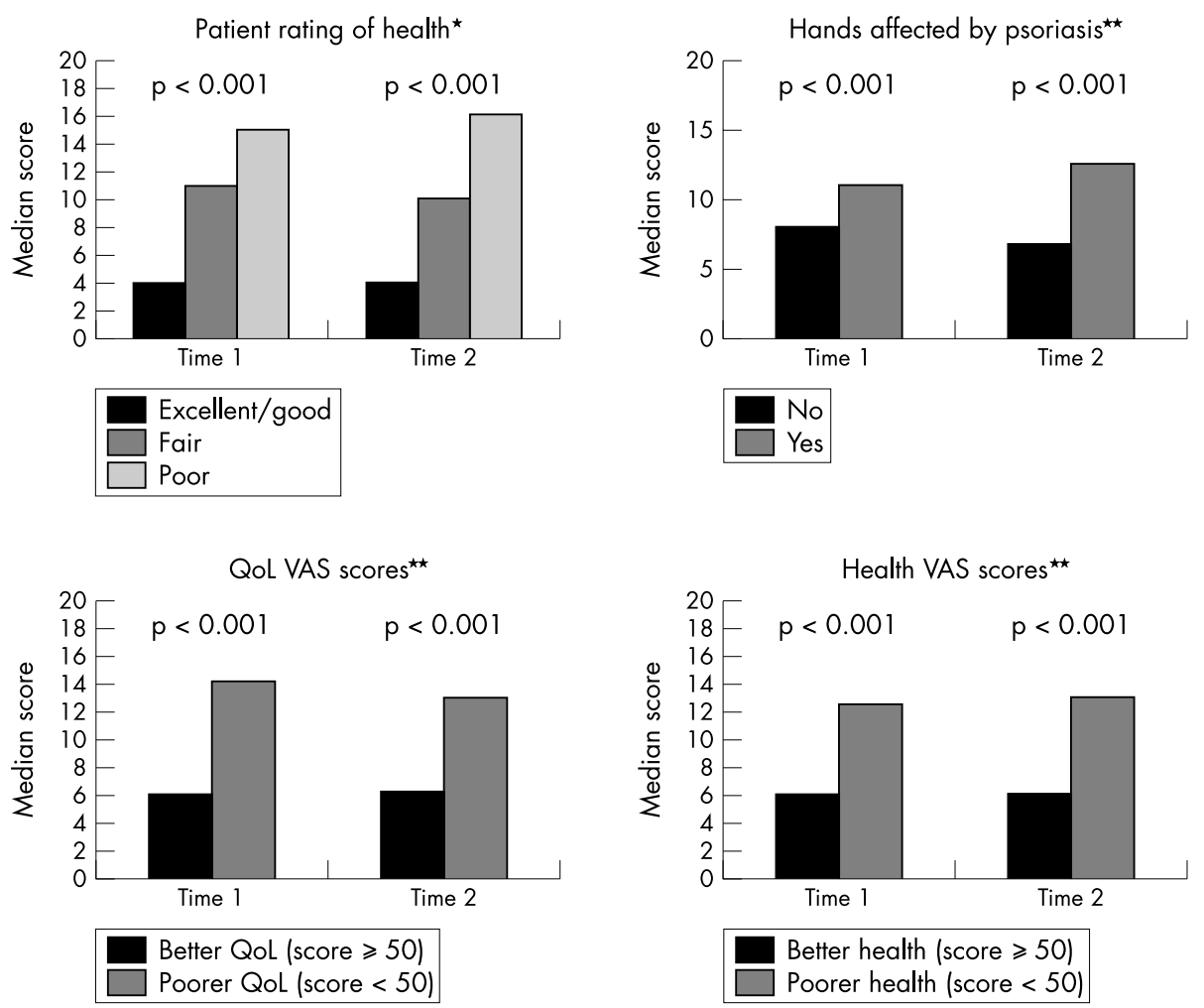

Figure 2 Associations between $\mathrm{Ps}_{\mathrm{S}} \mathrm{AQ} \mathrm{OL}$ scores and patients' ratings of general health, quality of life, and visibility of skin lesions.

effectiveness of interventions from the patient's perspective. Furthermore, the items included in the PsAQoL will be incorporated into a rheumatology item bank, allowing comparisons to be made between the QoL of patients with different rheumatic conditions.

\section{ACKNOWLEDGEMENTS}

The study was funded by the Arthritis Research Campaign in the UK. The authors are particularly grateful to the Psoriatic Arthropathy Alliance and to the many patients who participated in the development and testing of the PsAQoL.

\section{Authors' affiliations}

S P McKenna, L C Doward, D Whalley, Galen Research, Manchester, UK

A Tennant, P Emery, Academic Unit of Musculoskeletal and Rehabilitation Medicine, University of Leeds, Leeds, UK D J Veale, St Vincent's University Hospital, Dublin, Ireland

\section{APPENDIX}

\section{Final 20 items of the PsAQoL}

The PsAQoL must not be reproduced, used or adapted into other languages without permission of the authors. UK researchers wishing to use the measure should contact Professor Alan Tennant at the Academic Unit of Musculoskeletal and Rehabilitation Medicine, The University of Leeds, 36 Clarendon Road, Leeds LS2 9NZ. UK (Email: AlanTennant@ compuserve.com). Commercial organisations and overseas researchers should contact Dr Stephen P McKenna at Galen Research, Enterprise House, Lloyd Street North, Manchester M15 6SE, UK (Email: smckenna@galen-research.com).

- I feel tired whatever I do

- I find it difficult to have a good wash

- It's too much effort to go out and see people
- I feel there's no enjoyment in my life

- I feel I am losing my independence

- I often get angry with myself

- I can't do the things I want to do

- I feel older than my years

- I'm unable to join in activities with my friends or family

- It limits the places I can go

- I have to push myself to do things

- I am easily irritated by other people

- I have to keep stopping what I'm doing to rest

- I feel dependent on others

- It takes me a long time to get going in the morning

- I take it out on people close to me

- I can't do things on the spur of the moment

- I feel like a prisoner in my own home

- I have to limit what I do each day

- It puts a strain on my personal relationships

\section{REFERENCES}

1 Gladman DD, Espinoza LR. International symposium on psoriatic arthritis J Rheumatol 1992;19:290-1.

2 Veal D, Rogers S, Fitzgerald O. Classification of clinical subsets in psoriatic arthritis. Br J Rheumatol 1994;33:133-8.

3 Gupta AK, Grober JS, Hamilton TA, Ellis CN, Siegel MT, Voorhees JJ, et al. Sulfasalazine therapy for psoriatic arthritis: a double blind placebo controlled study. J Rheumatol 1995;22:894-8.

4 Husted JA, Gladman DD, Cook RJ, Farewell VT. Responsiveness of health status instruments to changes in articular status and perceived health in patients with psoriatic arthritis. J Rheumatol 1998;25:2146-55

5 Blackmore MG, Gladman DD, Husted J, Long JA, Farewell VT. Measuring health status in psoriatic arthritis: the Health Assessment Questionnaire and its modification. J Rheumatol 1995;22:886-93.

6 Husted JA, Gladman DD, Long JA, Farewell VT. A modified version of the Health Assessment Questionnaire (HAQ) for psoriatic arthritis. Clin Exp Rheumatol 1995:13:439-43. 
7 Duffy CM, Watanbe Duffy KN, Gladman DD, Brubacher BB, Buskila D, et al. The utility of the arthritis impact measurement scales for patients with psoriatic arthritis. J Rheumatol 1992;19:1727-32.

8 Husted J, Gladmann DD, Farewell VT, Long JA. Validation of the revised and expanded version of the Arthritis Impact Measurement Scales for patients with psoriatic arthritis. J Rheumatol 1996;23:1015-19.

9 Husted J, Gladmann DD, Long JA, Farewell VT. Relationship of the Arthritis Impact Measurement Scales to changes in articular status and functional performance in patients with psoriatic arthritis. J Rheumatol 1996;23:1932-7.

10 Zangger $\mathbf{P}$, Gladman DD, Bogoch ER. Musculoskeletal surgery in psoriatic arthritis. J Rheumatol 1998;25:725-9.

11 Taccari E, Spadaro A, Rinaldi T, Riccieri V, Sensi F. Comparison of the Health Assessment Questionnaire and Arthritis Impact Measurement Scale in patients with psoriatic arthritis. Rev Rhum Engl Ed 1998;65:751-8.

12 Husted JA, Gladmann DD, Farewell VT, Long JA, Cook RJ. Validating the SF36 health survey questionnaire in patients with psoriatic arthritis. J Rheumatol 1997;24:511-17.

13 Nichol MB, Margolis JE, Lippa E, Rowe M, Quell J. The application of multiple quality of life instruments in individuals with mild-to-moderate psoriasis. PharmacoEconomics 1996; 10:644-53.

14 Rapp SR, Feldman SR, Exum ML, Fleischer AB Jr, Reboussin DM. Psoriasis causes as much disability as other major medical diseases. J Am Acad Dermatol 1999:41:401-7.

15 Holmes SJ, McKenna SP, Doward LC, Shalet SM. Development of a questionnaire to assess the quality of life of adults with growth hormone deficiency. Endocrinol Metab 1995;2:63-9.

16 Wagner TH, Patrick DL, McKenna SP, Froese MA. Cross-cultural development of a quality of life measure for men with erection difficulties. Qual Life Res 1996;5:443-9.

17 McKenna SP, Doward LC, Mackenzie Davey K. The development and psychometric properties of the MSQOL; a migraine-specific quality-of-life instrument. Clin Drug Invest 1998;15:413-23.

18 Doward LC, McKenna SP, Kohlmann T, Niero M, Patrick D, Spencer B, et al. The international development of the RGHQoL: a quality of life measure for recurrent genital herpes. Qual Life Res 1998;7:143-53.

19 McKenna SP, Cook SA, Whalley D, Doward LC, Richards HL, Griffiths CEM, et al. Development of the PSORIQoL, a psoriasis-specific measure of quality of life designed for use in clinical practice and trials. Br J Dermatol 2003; 149:323-31
20 de Jong Z , van der Heiide D, McKenna SP, Whalley D. The reliability and construct validity of the RAQoL: a rheumatoid arthritis-specific quality of life instrument. Br J Rheumatol 1997;36:878-83.

21 Doward LC, Spoorenberg A, Cook SA, Whalley D, Helliwell PS, Kay L, et al. The development of the ASQoL: a quality of life instrument specific to ankylosing spondylitis. Ann Rheum Dis 2003;62:20-6.

22 Dewar AL, Doward LC, Whalley D, McKenna SP, Tennant A, Emery P, et al Impact of systemic lupus erythematosus (SLE) experienced from the patients' perspective. Proc Br Psychol Soc 2001;9:64.

23 Berzon R, Hays RD, Shumaker SA. International use, application and performance of health-related quality of life instruments. Qual Life Res 1993;2:367-8

24 Hunt SM, McEwen J, McKenna SP. Measuring health status. London: Croom Helm, 1986.

25 Brazier J, Harper R, Jones NMB, O'Cathain A, Thomas KJ, Usherwood T, et al. Validating the SF-36 health survey questionnaire: new outcome measure for primary care. BMJ 1992;305:160-4.

26 Ruta DA, Abdalla MI, Garratt AM, Coutts A, Russell IT. SF-36 health survey questionnaire: I Reliability in two patient based studies. Qual Health Care 1994;3:180-5.

27 Rasch G. Probabilistic models for some intelligence and attainment tests. Chicago: University of Chicago Press, 1960. (Reprinted 1980.)

28 Angoff WH. Perspectives on differential item functioning methodology. In: Holland PW, Wainer H, eds. Differential item functioning. Hillsdale, New Jersey: Lawrence Erlbaum, 1993.

29 Nunally JC Jr. Psychometric theory. 2nd ed. New York: McGraw-Hill, 1978.

30 Weiner E, Stewart B. Assessing individuals. Boston: Little Brown, 1984

31 Whalley D, McKenna SP, de Jong Z, van der Heijde D. Quality of life in rheumatoid arthritis. Br J Rheumatol 1997;36:884-8.

32 Wolfe F, Flowers N, Burke TA, Arguelles LM, Pettitt D. Increase in lifetime adverse drug reactions, service utilization, and disease severity among patients who will start COX-2 specific inhibitors: quantitative assessment of channeling bias and confounding by indication in 6689 patients with rheumatoid arthritis and osteoarthritis. J Rheumatol 2002;29:1015-22.

33 Verhoeven AC, Boers M, van der Linden S. Responsiveness of the core set response criteria and utilities in early rheumatoid arthritis. Ann Rheum Dis 2000;59:966-74.

34 Streiner D, Norman G. Health measurement scales. Oxford: Oxford University Press, 1989.

35 McHorney CA, Cohen AS. Equating health status measures with item response theory. Med Care 2000;38(suppl 2):43-59. 